\title{
But Are They Learning? Getting Started in Classroom Evaluation
}

\author{
Melissa H. Dancy ${ }^{*} \ddagger$ and Robert J. Beichner ${ }^{\dagger}$
} *Department of Physics, Davidson College, Davidson, North Carolina 28035; ${ }^{\dagger}$ Department of Physics,
North Carolina State University, Raleigh, North Carolina 27695

Submitted April 2, 2002; Revised May 21, 2002; Accepted May 28, 2002

Monitoring Editor: Marshall Sundberg

\begin{abstract}
There are increasing numbers of traditional biologists, untrained in educational research methods, who want to develop and assess new classroom innovations. In this article we argue the necessity of formal research over normal classroom feedback. We also argue that traditionally trained biologists can make significant contributions to biology pedagogy. We then offer some guidance to the biologist with no formal educational research training who wants to get started. Specifically, we suggest ways to find out what others have done, we discuss the difference between qualitative and quantitative research, and we elaborate on the process of gaining insights from student interviews. We end with an example of a project that has used many different research techniques.
\end{abstract}

Keywords: qualitative research, research methods, interviews.

\section{INTRODUCTION}

In recent years, research on the teaching and learning of science has increased, which has yielded many positive benefits for students. There have always been scientists engaged in educational research related to their disciplines. However, since 1990 the number of scientists taking a strong professional interest in educational research has risen, which has increased our understanding of science teaching and learning.

Cell Biology Education represents a commitment by biologists to focus on improved teaching and learning in biology backed by peer-reviewed work. It will provide a wonderful avenue of communication and, it is hoped, inspiration. Nevertheless, how do you undertake a study of teaching and learning? Can you gain valuable insights from your own small class of students? The answer is a resounding yes. In the rest of this article we argue the necessity of such research and provide a brief guide to appropriate methodology.

\section{FORMAL EDUCATIONAL RESEARCH VERSUS OBSERVANT TEACHER}

It could be said that every conscientious instructor engages in educational research. All courses include some measures of student success, such as exams, homework, and laboratory write-ups. The conscientious instructor uses the outcomes of these measures to inform future teaching. In addition, we get the formal feedback of end-of-semester student evaluations, and for receptive instructors, interactions with students, to help us assess our own teaching.

DOI: 10.1187 /cbe.02-04-0010

‡Corresponding author. E-mail address: medancy@davidson.edu.
By paying attention to the feedback of a normal course, we can learn a lot about our teaching and our students' learning. However, equating this endeavor with educational research is like saying a child interacting with his or her world is conducting scientific research. The child will function in the physical world very well, but she will still have basic misconceptions that will lead her to erroneous predictions. Feedback that comes from teaching a course can be enlightening, but ultimately its worth is limited. It is anecdotal in nature, not based on rigorous testing of a hypothesis and the elimination of alternatives, and it cannot be generalized. Simply because a method worked well in one course, with a specific group of students, does not mean it will work well in other courses.

Just as a rigorous study of the physical world was required to change scientific thought from an Aristotelian point of view to a Newtonian (and eventually to an Einsteinian) viewpoint, a rigorous study is necessary for us to make true progress in the realm of teaching and learning biology. A study of teaching and learning, based on rigorous research methods, can lead to a worthwhile increase in our ability to help students learn. The results may be surprising and they may not be what we want to find. However, done well, research can provide us with many valuable insights that could not be obtained by simply paying attention to our own teaching.

\section{WHY BIOLOGISTS SHOULD CONDUCT EDUCATIONAL RESEARCH}

There are fields specifically devoted to educational research. They are populated by talented people who are trained in educational research methods, who have devoted their lives to becoming experts in educational issues, and who work within fully developed professional fields. So what does a 
biologist, with no formal training in social science research, have to offer?

Biologists may not be experts in education, but they are experts in biology. This adds a distinct advantage to research in biology education. To make sense of students' concepts about cell biology, the researcher must have a firm understanding of the concepts. Although the necessity of strong content knowledge is most obvious when student learning in upper-level courses is being researched, it is also important in introductory-level courses. Areas of student difficulty in the introductory level often persist well into graduate school. Put simply, there are many insights into student learning of biology that are best discovered by someone intimately connected with the discipline.

In addition to being experts in biology, teaching biologists are familiar with biology education. An education researcher may know more of the theoretical underpinnings of teaching, but the teaching biologist has spent hours in the biology classroom and has an enormous range of practical experiences to draw on. It is difficult to research teaching and learning in a course that the researcher has never taught. For this reason, we (the authors) argue that understanding of student learning in biology courses must come from biologists.

Biologists also have a practical advantage when it comes to biological education research. Teaching biologists have easy access to potential research opportunities. The easiest type of research to do is on their own courses because it is sometimes difficult to ask someone else for precious class time or student data. Biologists also have the most control in their own courses, which gives them more freedom in design.

Now that we have argued the advantages of biologists' conducting educational research, let us turn the tables a bit with a word of caution. Because biologists are so intimately connected to biology, they are in a position to develop the knowledge base of biology education in unique ways. However, the greatest mistake scientists make when they undertake educational research is to ignore the expertise from the field of education. Although it would be unfathomable for a researcher to begin a study of cell biology without first undertaking a study of what others have done in the area, scientists often conduct educational research, and even formally present results, without ever taking the time to find out what has been done in the past and to learn from others with related interests.

Past research in education has been successful. Many hardworking, intelligent, and talented people have worked to develop the knowledge base of education and the methods of obtaining this knowledge. Let us not underestimate what they have to offer, nor belittle their contributions. Instead, let us learn from them so that we can use our unique knowledge and skills to contribute to biology education.

The Appendix provides resources to be used as an initial gateway into the world of educational research. Following is a list of resources related to the professional activity of evaluating your own classroom.

\section{Carnegie Academy for the Scholarship of Teaching and Learning (CASTL)}

This program focuses on supporting and encouraging the scholarship of teaching and learning. Through the CASTL web site, you will find numerous thought-provoking and helpful resources: www.carnegiefoundation.org/CASTL/.

\section{Opening Lines: Approaches to the Scholarship of Teaching and Learning}

Edited by P. Hutchings (2000), this book is a collection of eight essays. "Each of the eight authors tells the story of her or his efforts at 'opening lines' of inquiry into significant issues in the teaching and learning of the field" (from book introduction)

\section{Classroom Research: Implementing the Scholarship of Teaching}

According to the publisher of this book by Cross and Steadman (1996), "Classroom Research details a collaborative process for investigating teaching and learning issues. This technique engages teachers in problem-based discussions, integrates their teaching experience with recent research and theory on learning, and gives examples of Classroom Assessment and Classroom Research projects that can be carried out in any classroom."

\section{The Journal of Scholarship of Teaching and Learning (JoSoTL)}

According to its mission statement, the JoSoTL is "designed to encourage all instructors to engage in the discussion of the Scholarship of Teaching and Learning (SoTL), and to become involved in the sharing of knowledge and learning about the teaching-learning process." It publishes classroombased research as well as discussions related to the scholarship of teaching and learning. Articles are available online at www.iusb.edu/ josotl/.

\section{METHODS OF EDUCATIONAL RESEARCH}

Research in biology is very different from educational research. In biology it is possible, to a close approximation, to carefully control all variables. A good experiment can be repeated with essentially the same results. Also, instruments can be developed that give direct measurements of interesting phenomena. Conversely, when we are researching human behavior, it is extremely difficult to control important variables. Ethics often hinder this control because an educator cannot expose students to potentially harmful treatments nor can he or she ethically withhold a treatment believed to benefit them. This is particularly true when we are working with students enrolled in a course rather than volunteer research participants. Even with ethics aside, there are so many variables that could potentially affect someone's ability to learn that it is impossible to control them all. Students bring a large variety of backgrounds, past experiences, expectations, motivations, and emotions with them into the classroom. Each of these will interact with a particular curriculum in a unique way.

Therefore how can research be conducted to give meaning to the results? It is impossible to thoroughly answer this question here. What follows is not intended to be a definitive guide to the educational researcher but rather an introduction to some of the most commonly used methods.

\section{Quantitative versus Qualitative Research Methods}

There are essentially two forms of educational research: quantitative (or statistical) and qualitative. In the past, most research was quantitative in nature, fashioned after the highly successful hard-science 
research methods. Since the 1990s, educational researchers have embraced qualitative research with the recognition that research on the human mind is fundamentally different from research on physical systems. Qualitative methods are used for depth of knowledge and quantitative methods are used for breadth and generalizability. We cannot emphasize this enough: the best research designs employ both methods.

Most readers of this article will be familiar and comfortable with the ideas behind quantitative research. Because of this, and because quantitative research methods are well documented (e.g., Hopkins, 1998), we will not attempt a discussion of statistical research methods here. However, many readers will be uncomfortable with qualitative research because it is so different from the formal training of a biologist. Nonetheless, it is a vital component of educational research and should not be overlooked. What follows is a brief discussion of the most useful and common qualitative research methods for education.

\section{Qualitative Research}

Statistical research is well suited for drawing generalizable and repeatable conclusions based on a large sample of students, but it lacks depth. For example, suppose you use a particular approach in your course that you believe will lead to a greater understanding of transcription. You design a test that measures student understanding and give it to numerous students taught by using your approach and a traditional approach. You find that the students taught under your new method significantly outperform their peers. You come to the conclusion that your approach is superior. If your test and research methods were well designed, your conclusion is valid. You know your method is superior, but you have no data that tell you why the method was so successful. You probably have hypotheses about why the method worked so well (you had some reason to try it in the first place), but you do not know for sure. To properly answer the question of why, you must engage in qualitative research.

Qualitative research is also enormously helpful when you are initially investigating a particular area and are in the process of determining what questions might be interesting to study. The data of qualitative research are incredibly rich. Although this richness is an asset, it also makes qualitative data difficult and time consuming to analyze.

The National Science Foundation (NSF) has developed a detailed introduction to qualitative research geared toward the scientist. This introduction, User-Friendly Handbook for Mixed Method Evaluations, is excellent and can be found online at www. nsf.gov/pubsys/ods/getpub.cfm?nsf97153.

In the following subsections, we describe student interviews-a commonly used qualitative research tool. Most of what applies for interviews also applies for other types of qualitative research such as classroom observations and open-ended surveys. You are urged to read the NSF's handbook, mentioned above, for a more complete description of qualitative research.

Interviews. It is difficult to find out exactly what students are thinking. It would be useful if there were a probe that we could connect to the human brain that could give us information directly. Unfortunately, we must gauge thinking indirectly. The interview provides one mechanism through which we can begin to access students' thoughts, although it is certainly not foolproof. Most students are not particularly aware of their own thought processes and therefore have difficulty articulating them. They also have a tendency to filter out thoughts for various reasons. Interviews must be carefully structured to obtain the most information, and the results must be carefully analyzed.

Formal interviews are very different from the kind of casual interactions that occur between an instructor and a student. When a student comes to your office, your mission is to help the student. You often provide him or her with feedback and answer his or her questions. In an interview, your role is different. Your mission is to find out how students are thinking. You do not want to direct their

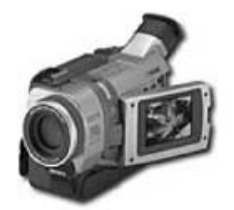

(A)

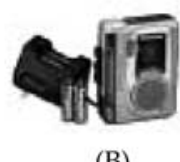

(B)
Figure 1. (A) Sony video camera and (B) Panasonic audio recorder.

answers, so you must refrain from providing feedback and may not correct their errors.

The process of interviewing can be problematic and requires skill on the part of the interviewer. What follows is not a definitive guide to interviewing but rather an introduction with some practical advice for those who may not have previously considered it as a research tool.

Interviews must be audiotaped and are often videotaped as well (see Figure 1). Such taping is particularly important when students must do something, such as interact with a computer or solve a problem, during the interview. When more than one student is being interviewed at a time, video recordings help determine the owner of each comment. In addition, video captures interesting behaviors such as hand gestures and facial expressions. The quality of audio recordings is always an issue, so be sure to use the best equipment you can obtain and test it before beginning the interview. The recording equipment may seem intrusive and makes most students nervous at first. However, once the interview is under way most people ignore the recording equipment if attention is not drawn to it.

Once the interviews are completed, they need to be transcribed. Transcription is a necessary but tedious task. In our experience, it takes about five times longer to transcribe an interview than it does to conduct it. Because of the long time involved, you may want to hire someone to do the transcription for you. Professional transcription services (whose main clientele are doctors and lawyers) can be expensive. Because transcription is easy to learn and you do not need $100 \%$ accuracy (you need to go over the tape yourself anyway), student workers are an adequate, less expensive alternative. If you choose to do the transcription yourself, investment in a transcription machine is a good idea (Figure 2). Such machines are easy to use and the ratio of transcribing time to interview time is closer to 8:1 without one. Voice-recognition software is another alternative, but at this point it does not offer any time savings over manual transcription.

After you have transcribed the interview, you must analyze it. With statistical data, great care must go into collecting the data. Once the data are collected, the analysis is mostly a matter of following the rules of statistics. The analysis of interview data is not so clear cut. In general the following list provides a good start:

- We all have our own perspectives and biases. You must be aware of yours. Are you likely to look for particular meanings while discounting others? What are your expectations? What words may hold different meanings for you and your students? Your perspective will taint your analysis. You must safeguard against unjustified assumptions as much as you can.

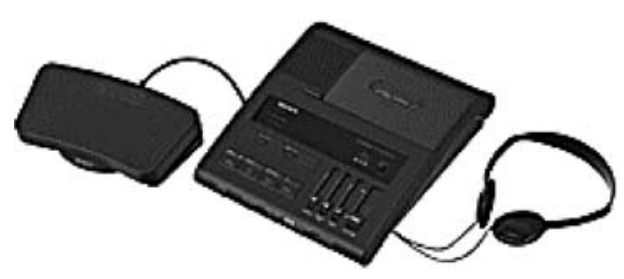

Figure 2. Sony transcription machine. 
- Carefully read through the transcript, making notes of anything that strikes you as interesting. You may need to repeat this step several times.

- Once you have some hypotheses, test them by reading through your transcript and looking for supporting or contradictory evidence. You must be very careful. Humans have a tendency to focus on what supports our ideas and ignore or discount what does not. Once you have developed assertions from your interviews, you will need to do a through job of backing them up with evidence.

- It is usually helpful to develop a coding scheme to analyze an interview. For example, suppose you have interviewed students answering a particular conceptual question. After reading through the interviews you develop a coding scheme that identifies the types of mistakes students made. You can then code all your interviews on the basis of this scheme. This type of analysis can be very useful. An example is shown below in Table 1 .

- Once you have developed a coding scheme, have a respected colleague use your scheme to code a sample of the interview data. If your colleague does not understand your scheme well enough to approximately match your coding, you need to go back and refine either your scheme or your coding. It is unlikely that you and your colleague will agree on all codes, but you should be able to resolve any discrepancies. This is an important step in establishing the validity and reliability of your analysis.

- After you have the results of the qualitative analysis, look back at any statistical data you may also have collected. There should not be any contradictions. If there are, you must resolve them. If you do not have any statistical data, use the results of your interview analysis to formulate a statistical test of your hypothesis. For example, suppose you interviewed 10 students and found that half of them believe that the steps of mitosis are discrete rather than continuous. You believe that this is a common misconception. You could then give a multiple-choice version of the question to 300 students to see if the misconception is as common as you believe.

How many interviews should you conduct and analyze? In statistical research, it is important to have a large sample. A statistical study reporting results based on 10 students would not be given much respect. Qualitative research is different. It is not practical to conduct and analyze 300 interviews, nor is it necessary. When you take statistical data from one student, you get only a small piece of information. In contrast, qualitative data are enormously rich. An hour-long interview with a student will provide you with more information than you will ever be able to fully analyze. There are excellent studies that were done with three or fewer participants. How many you need will depend on your particular project. If you plan to spend half an hour or so with individual students, probing them on their understandings of a narrow topic or their opinions, after about 10-15 interviews you will probably have covered most of the aspects of the topic. As you are doing the interviews, you will reach a point at which you feel as if there is nothing new to be found. At this point you probably have enough data.

Besides the general interview in which you might ask students their perceptions of the course or their learning, there are two specific types of interviews that can be very beneficial for science education: the think-aloud interview and the focus-group interview.

Think-Aloud Interviews. The think-aloud interview is a useful tool for discovering the thought processes of students as they tackle a cognitive task. The idea is to present the student with a task to complete and ask him or her to talk out loud about what he or she is thinking and doing. You should be able to get more information by using this method than you would if you simply asked the students to answer a question and then tell you their thought processes.

Table 1. Data from a think-aloud interview in which a student was asked to find the velocity and speed of a particle ${ }^{a}$

\section{Raw transcript}

Coded transcript

RQ (Ok for the first part, (a),

SC (velocity is displacement over time and you subtract final minus initial displacement over final time minus initial time. So at time, $\mathrm{t} 2$, is our final time; $\mathrm{t} 0$ is our initial time. [[long pause]] Ok displacements are the same, from, $x 0$ is the initial point to [[long pause]] displacement is from the original position.)

MD (So from 0 is $-8.5 \mathrm{~m}$ from the original point.)

MA (So its velocity is 8.5 negative minus 0 equals 8.5 divided by 2 . Its average velocity is $-4.25 \mathrm{~m} / \mathrm{s}$.)

SC (Whereas speed deals with the total distance traveled, not displacement,)

DQ (so here we'll see how far it travels to on the positive $x$-axis as well as on the negative $x$-axis.)

MD (Ok it goes as far as 3.5 and then back to 8.5)

MA (so we'll subtract negative 8.5 . So the total distance traveled for that is 12 meters both on the positive and negative $x$ axis. So we'll subtract that from the initial position at 0 . So its speed is $6 \mathrm{~m} / \mathrm{s}$.)
Coding scheme

RQ-Read and interpret question.

RA-Read and interpret animation.

SE-Search for equation.

SC-State concept, principle, definition, or equation.

DQ-Decide what quantities or measurements are needed.

MD-Measure data.

SD-State what data have been measured or what data are known.

DS-C-Do something-control animation.

DS-Do something-look in book for equation, write information down, etc.

MA-Mathematically analyze data and equations.

CA-Check answer or check approach; see if approach is consistent and appropriate.

EX-Express personal feelings such as doubt, certainty, etc.; personal reflection.

??-Meaning of statement cannot be accurately determined. the total distance traveled for that is 12 meters both on the positive and negative $x$ axis. So we'll subtract that from the initial position at 0 . So its speed is $6 \mathrm{~m} / \mathrm{s}$.

${ }^{a}$ From Titus (1998). 
If you ask students for their thoughts after the fact, they will usually give you a condensed version and leave out dead ends in their thinking. Often it is the process, not the final answer, that you are most interested in.

The think-aloud interview can be stressful for students who are not accustomed to sharing every inner thought they have. It is important to set them at ease at the beginning. This can be done by assuring them that the interview is confidential, that what they say will have no bearing on their grade in a course, and by allowing them to warm up. The warm-up is important because it allows them extra time to forget about the recording equipment and it gets them accustomed to speaking out loud. The warm-up question or task could be anything simple and easy. For example, you might ask them to determine the number of windows in their houses or to complete a very simple version of tasks that they will be given later. Remind them to talk out loud and to say everything they are thinking without trying to judge the correctness of their thoughts. There is some debate about whether or not the interviewer should remind students to keep talking if they fall into silence. Most students will focus on their own thinking and cease to speak at some point. We interject with "What are you thinking now?" to get them talking again. Others believe this approach distracts students. Do whatever seems appropriate to you as long as you mostly stay out of the students' way and do not lead them any more than is necessary.

Focus-Group Interviews. Focus-group interviews involve interviewing more than one student at a time. The dynamics of the interview is very different when multiple students are involved. For example, suppose you recently made major revisions to your course structure. You want to know how well you have done from the students' point of view. In this particular situation you will probably get more information if you interview students in groups. First, the students are likely to be more comfortable expressing criticism of your course when they are not alone in that expression. Second, the students will feed off one another, adding to what others have said and disagreeing at times. Consequently, the focus-group interview can be a powerful tool.

\section{EXAMPLE OF RESEARCH}

The strongest qualitative research utilizes a variety of techniques to investigate a question, "triangulating" toward the answer much as multiple bearings by a sailor help ensure accurate navigation. In fact, the best studies often combine qualitative and quantitative approaches to benefit from the depth and resolution of the first method and the generalizability of the second. As a way of seeing how these very different techniques can be combined, we briefly describe a project in which a new classroom environment/pedagogy was being evaluated for its educational impact.

\section{SCALE-UP (Student-Centered Activities for Large Enrollment University Physics; www.ncsu.edu/per/scaleup.htm)}

Our first step in this curriculum-development effort was to list what we were trying to accomplish with the new pedagogy. This list included not only content-specific learning, but also building problem-solving skills and opportunities for collaborative learning. Once you have clearly defined objectives, you can devise ways to measure them. Because we had a wide-ranging set of desired outcomes, we needed a variety of assessment methods.

To help us ascertain whether students were learning the content, we utilized a bank of nationally normed conceptual tests. We gave these tests in a pre/post mode so that we could measure learning from the improvement of scores during the semester. The pretests were given before any instruction on the topic was presented in the experimental class. The posttests were taken after students had been taught the specific content, usually at the end of the semester. The normalized gain score (Hake, 1998) is used to allow easy comparison of students who may have underlying differences in preparation. It is the percentage of total possible gain and is calculated from the following equation:

$$
\langle g\rangle=\frac{\text { Actual Gain }}{\text { Possible Gain }}=\frac{\bar{x}_{\text {posttest }}-\bar{x}_{\text {pretest }}}{\text { Max.Score }-\bar{x}_{\text {pretest }}}
$$

By comparing the normalized gain of experimental classes and that of traditional classes, we could begin to quantify the benefits of the new teaching approach. Giving regular exam questions to students in the SCALE-UP classes and the control classes gave us specific information about the content area of the knowledge and problem-solving skills that were being improved. We had the luxury of a control class taught during the same semester as the experimental section. However, we could have used a previous semester's class as the control. It is helpful to establish a baseline before beginning an innovation. Other, coarser, statistics were also useful. Administrators were often interested in pass/fail rates, particularly for underrepresented groups.

Classroom observations can be very helpful. The observer needs to remain "outside" the class in the sense that he or she cannot answer students' questions about the material but must instead focus on recording what is happening in the classroom. There are various ways to do this. You can create a protocol in which a "sweep" of the room is conducted at regular time intervals. Alternatively, the observer can focus on a single student or team, or on how the instructor manages the class. Even something as simple as playing a videotape at high speed provides a glimpse of how an instructor moves around the room and what kinds of discussions occur. It is important that someone other than the instructor be involved in qualitative research because students often respond to questions with what they believe the teacher wants to hear.

Careful observations were made of what was occurring in the classroom. After the semester's notes were completed, the approximately 300 pages were reviewed multiple times. An assortment of colored highlighting pens allowed reviewers to quickly categorize observations recorded on photocopies of the original notes. After each reading, the categories were revised as needed. In some cases categories were combined; other times they were split. The purpose of organizing the data this way was to facilitate further analysis. Once a useful scheme was imposed on the data, all the examples fitting into each category (with its own highlighting color) were collected for further review. We were interested in seeing changes that took place during the semester and how these changes were influenced by the instruction and the learning environment. The first and last sets of categories extracted from the data are listed in Table 2. Although they seem similar, the first set is more vague than the second. When creating categories, you must be careful not to make them so broad that they are meaningless or so narrow that they apply to only a few isolated instances in the data.

A great deal can be learned from this type of review. For example, most of the first set of observation categories could 
Table 2. Sample of coding scheme used for classroom observations

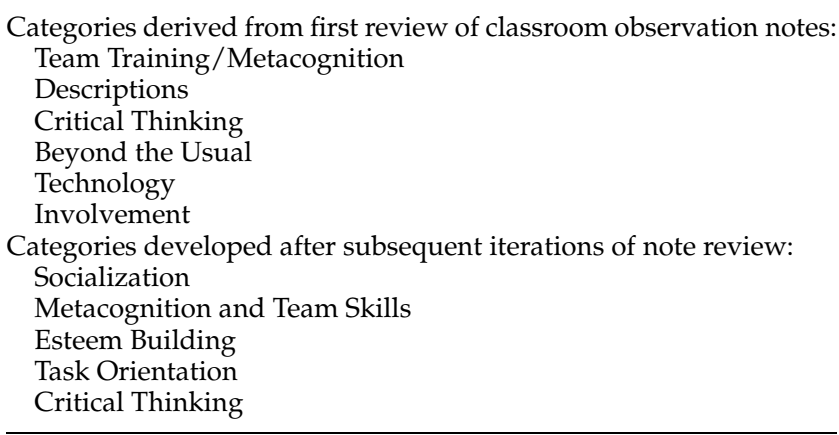

have been predicted. However, during our note review we were surprised at the frequency of praise coming from the instructor. We created a separate category for esteem building and decided that it was an important component of the learning environment. We followed up on this by reviewing and categorizing the notes left on the classwide electronic bulletin board. We were interested in communication among class members, so we had already planned to analyze the messages in the electronic bulletin board. Reiterating what we saw in the classroom observation notes, $13 \%$ of the messages from faculty to students contained some kind of positive reinforcement.

Additional qualitative investigations gave us insight into students' understanding as well as their feelings about the course. We interviewed students individually and in focus groups, as described earlier. We also collected portfolios of student work. Reviewing these documents can be interesting and is ongoing. For example, we are currently comparing group contracts (agreements made between collaborating team members to ensure success) to see what students have learned about how groups function. We are comparing contracts made at the beginning of the semester with those made halfway through, when new groups were assigned. A preliminary finding is that the contracts written after the students experienced group work for 7 weeks incorporated more detail as to how to handle problems that arise. For example, rather than simply stating: "Members will attend group meetings," students also listed consequences of nonattendance. This detail is something the students devised, and, we believe, clearly indicates their increasing ability to make groups function. The research methods utilized in the project continue to evolve as new ideas emerge from our analyses.

\section{RESOURCES FOR ADDITIONAL TOOLS AND INSIGHTS}

If you are just beginning to evaluate pedagogy and need a good place to start, you will find the following two resources helpful. Each offers a collection of techniques that can be used to evaluate a number of objectives.

\section{Field-tested Learning Assessment Guide (FLAG; www.wcer.wisc.edu/nise/cl1/flag/)}

This web site describes itself as offering "broadly applicable, self-contained modular classroom assessment techniques
(CATs) and discipline-specific tools for instructors interested in new approaches to evaluating student learning, attitudes and performance." If you are looking for a tool to use to assess a particular component of your course, this is a wonderful place to start.

\section{Classroom Assessment Techniques}

This book by Angelo and Cross (1993) provides an extensive discussion of classroom assessment and offers many insights that would be helpful to the teacher assessing his or her classroom. There are also descriptions of a large number of techniques that can be used to gain information about students and their learning. It is a valuable resource for the classroom teacher.

\section{CONCLUSION}

The benefit of having biology teachers study the teaching and learning of biology is their content knowledge and classroom experience. However, research in education, as in other fields, is a scholarly endeavor. A thorough literature review, careful data collection, and a reliable method of analysis are required. Quantitative and qualitative approaches provide different insights into student learning. The best research is often a combination of the two. Many resources are available for biologists interested in pursuing this area of research. Cell Biology Education hopes to become one of their valued resources.

\section{ACKNOWLEDGMENTS}

We are grateful to Malcolm Campbell for his direction and extensive feedback on this article and to Scott Franklin for his comments. We also thank the reviewers, whose comments and suggestions strengthened the article. We appreciate the support of the National Science Foundation (DUE - 9752365 and DUE - 0126439) and the U.S. Department of Education's Fund for the Improvement of Post-Secondary Education (FIPSE).

\section{REFERENCES}

Angelo, T.A., and Cross, K.P. (1993). Classroom Assessment Techniques: A Handbook for College Teachers, San Francisco: JosseyBass.

Cross, K.P., and Steadman, M.H. (1996). Classroom Research: Implementing the Scholarship of Teaching, San Francisco: JosseyBass.

Hake, R.R. (1998). Interactive-engagement vs. traditional methods: a six-thousand-student survey of mechanics test data for introductory physics courses. Am. J. Phys. 66, 64.

Hopkins, K.D. (1998). Educational and Psychological Measurement and Evaluation, Boston: Allyn \& Bacon.

Hutchings, P., ed. (2000). Opening Lines: Approaches to the Scholarship of Teaching and Learning. Menlo Park, CA: Carnegie Foundation for the Advancement of Teaching.

Titus, A.P. (1998). Integrating video and animation with physics problem solving: exercises on the World Wide Web. Ph.D. dissertation; North Carolina State University, Raleigh. 


\section{Appendix \\ Finding Out What Others Have Done}

As with any research, it is important to find out what others have done and how they have done it. In education, this can be difficult because educational knowledge is not centralized. There are a number of fields from which research comes. Look beyond the field of biology and biology education. You will find useful work from the fields of science education, educational psychology, educational technology, physics education, chemistry education, and other related fields. The following list is designed to be a gateway into the rather complex maze of educational research.

\section{EDUCATIONAL RESEARCH RESOURCES}

\section{Journal Databases}

ERIC and Education Abstracts are two searchable databases generally provided online by your library. They are a great place to start but the quality of what you will find will vary greatly because a variety of journals are included in the databases. Below is a list of research journals that we have found to be useful. It is not meant to be a complete list, just a starting point.

- Journal of Research in Science Teaching (JRST): This is the premier journal of science education research and generally contains articles from the fields of biology, chemistry, and physics.

- Cognition and Instruction: This is the premier journal of cognitive science. Articles usually focus on cognitive issues and are less discipline specific. Authors come from many fields, including psychology, education, and various scientific disciplines.

- American Journal of Physics Supplement: For the moment this is the main journal for physics education research. It will probably be replaced by something more substantial in the coming years as the field grows.

- Journal of Chemical Education: This is the main journal of chemistry education.

- Science Education: Studies cited in this journal often approach questions differently than is reported in JRST articles. As of this writing, the journal does not have a web page.

- International Journal of Science Education: This is a very high quality journal that brings in perspectives from around the world.

- Journal of Educational Psychology: This is the major journal for educational psychology.

- Journal of College Science Teaching: Although this is not strictly a research journal, there are often very useful descriptions of educational research in this journal.

- American Biology Teacher: Occasionally you will find a research study described here.

- Electronic Journal of Science Education: This new journal is freely available on the Web and is well worth investigating.

- Cell Biology Education: Obviously, we hope this journal becomes one of the most fruitful places to begin a literature review.

\section{REDCUBE (Research, Development, and Change in Undergraduate Biology Education; media4.physics. indiana.edu/ redcubel)}

REDCUBE is a web-based resource for biology education. According to Richard Hake, REDCUBE's author, it "contains 47 biology-educator profiles; 446 references (including 124 relevant to general science-education reform); and 490 hot-linked URL's on (a) Biology Associations, (b) Biology Teacher's Web Sites, (c) Scientific Societies and Projects (not confined to Biology), (d) Higher Education, (e) Cognitive Science and Psychology, (f) U.S. Government, and (g) Searches and Directories." Although he intended this resource to be for nonbiologists, it is so extensive that it is a valuable resource for biologists as well.

\section{Listservs}

In recent years a large number of listservs dealing with educational issues have come into being. Most of them have searchable archives. Chances are that if you are interested in a particular issue, someone else has recently posted about it. If you do not find anything useful in the archives, you can post your own question. The listserv can be a great tool for finding out the current thought in an area. Publication in a journal is usually a few years behind. Following is a list of a few relevant listservs to get you started.

- Biopi-l (e-mail list for biology teachers from kindergarten to university level): pages.infinit.net/missus/biopi/

- Forum for Teaching \& Learning in Higher Education: listserv.unb.ca/archives/stlhe-l.html

- Physlrnr (Physics Learning Research List): listserv. boisestate.edu/archives/physlrnr.html

- The American Educational Research Association: www. aera.net/resource/listarch.htm

- Chemed-L (chemistry education): www.optc.com/ chemed-l-thread/

- Tomorrow's Professor: learninglab.stanford.edu/projects/ tomprof/

\section{Web Search Engines}

It is amazing how much information can be pulled up on a computer in a matter of minutes. Most people have a web page now that describes their work. They generally provide related references, links, and downloads. A simple web search is always a great place to start.

\section{TYPES OF EDUCATIONAL LITERATURE}

As you make your way through the educational literature from the various resources, be aware that two types of articles exist. There are those that are written primarily for the teacher and those that are research reports. Those for the teacher focus on how to implement a particular idea into the classroom. They often lack the details that would allow an individual to make a judgment regarding the quality of the idea. Many of 
these articles are antecdotal and are based on teaching experiences rather than on rigorous research.

Other articles are research articles. If an article is a research report, it should clearly describe the research method and may or may not be directly applicable to the classroom. The re- search method should be justified. Simply discussing a classroom innovation with students during office hours does not constitute research. Unfortunately, some of these "studies" are presented as research. Be critical of what you see by setting high standards for others as well as for yourself. 